\title{
ADMINISTRATIVE CAPACITY FOR THE IMPLEMENTATION OF INTEGRATED TERRITORIAL INVESTMENTS FOR REGIONAL DEVELOPMENT IN BULGARIA
}

\author{
Evelina Parashkevova ${ }^{1 *}$, Michail Chipriyanov ${ }^{2}$, Elitsa Lazarova ${ }^{3}$, Nadezhda \\ Veselinova ${ }^{4}$, Yuliyan Gospodinov ${ }^{5}$ \\ ${ }^{1}$ Assoc. Prof., PhD, D. A. Tsenov Academy of Economics - Svishtov, BULGARIA, \\ e.parashkevova@uni-svishtov.bg \\ ${ }^{2}$ Assoc. Prof., PhD, D. A. Tsenov Academy of Economics - Svishtov, BULGARIA \\ m.chipriyanov@uni-svishtov.bg \\ ${ }^{3}$ Head Assist. Prof., PhD, D. A. Tsenov Academy of Economics - Svishtov, BULGARIA, \\ e.lazarova@uni-svishtov.bg \\ ${ }^{4}$ Head Assist. Prof., PhD, D. A. Tsenov Academy of Economics - Svishtov, BULGARIA, \\ n.veselinova@uni-svishtov.bg \\ ${ }^{5}$ Head Assist. Prof., PhD, D. A. Tsenov Academy of Economics - Svishtov, BULGARIA, \\ y.gospodinov@uni-svishtov.bg \\ ${ }^{*}$ Corresponding Author
}

\begin{abstract}
The report emphasizes the role of the human factor, its knowledge and skills to ensure effective and efficient implementation of the integrated approach in regional development and achieving sustainability. The adoption of a new planning approach comes in response to the impossibility of tackling key issues in achieving cohesion between the regions in the European Union (EU) with traditional instruments. The aim of the article is to outline a conceptual competency model, with key knowledge and skills, of planning experts and their role in the implementation of integrated public policies. The subject of research is the knowledge and skills for regional development planning in the context of integrated territorial investments, and the object is the administrative structure in Bulgaria, responsible for the implementation of this approach - the regional development councils. The commitment of regional development councils to the process of financing and implementation of strategic documents based on the integrated territorial investment approach inevitably requires the expertise and organization of work in order to effectively implement the approach and achieve appropriate and sustainable regional development. The article includes a review of the scientific literature regarding organizational and administrative aspects for the implementation of integrated territorial investments for development in the EU and in Bulgaria and the requirements for the competencies of institutions to ensure the integration of planning documents and practices at different hierarchical levels. The results of an empirical study of the capacity for planning and implementation of regional development policies in Bulgaria are presented, critically analyzing the existing practices, approaches and accumulated expertise regarding the implementation of the fundamentally new for the public sector in Bulgaria integrated planning approach. The necessary competencies of the planner are outlined through the tools of the competence approach, with special attention paid to IT competencies. On this basis, recommendations are made for capacity building in specific areas, which are largely essential for the effective management of regional development at the administrative and operational level.
\end{abstract}

Keywords: Competence approach, regional development, planning 


\section{LITERATURE REVIEW ON ORGANIZATIONAL AND ADMINISTRATIVE ASPECTS FOR THE IMPLEMENTATION OF INTEGRATED TERRITORIAL INVESTMENTS FOR DEVELOPMENT IN THE EUROPEAN UNION AND IN BULGARIA}

The Integrated Territorial Investments (ITI) in the European Union began to be seriously discussed in 2013. That is when the cohesion policy for the period 2014-2020 and the regulation on generally applicable provisions were adopted (Regulation (EU) № 1303/2013 of the European Parliament and the Council, 2013) and in the Bulgarian strategic framework these changes are introduced in the planning for the period 20212027.

ITI apply a horizontal approach that provides access to several priority axes of one or more operational programmes in order to ensure an integrated strategy for a given territory (Integrated teritorial investments, 2014). At the pan-European level, ITI are carried out in the presence of:

- A territory with certain (common) characteristics or potentials for development and the existence of an integrated strategy for territorial development;

- A package of actions related to thematic objectives of the priority axes of the operational programmes and corresponding to the objectives for development of the territorial strategy;

- Administrative management of the ITI - managing authority of the operational programme, intermediate bodies, local authorities for regional development, non-governmental organizations, etc., which perform some or all tasks related to the management and implementation of the ITI.

To achieve higher efficiency and effectiveness of actions in the financing of ITI are used combinations of different European structural and investment funds (ESIF): European regional development fund (ERDF); European social fund (ESF); Cohesion fund (CF); European agricultural fund for rural development (EAFRD); European maritime and fisheries fund (EMFF).

Projects that rely on funding from sources other than national operational programs, such as own funds, loans, state or municipal budgets, a fair transition fund, an instrument for reconstruction and sustainability, etc., are encouraged. When selecting such projects, higher ratings are given due to the increased synergy and integrated nature of the investments.

In order for a project to be considered integrated, it must meet at least one of the following conditions:

1) To involve several types of stakeholders (public authorities, private stakeholders, non-governmental sector);

2) To cover various administrative territories (different municipalities, regions);

3) To carry out interventions from various sectors.

During the 2014-2020 programming period, not all Member States in the EU implement ITI in their regional policies. Innovators in integrating the new approach are Belgium, the Czech Republic, Finland, France, Germany, Italy, the Netherlands, Romania, Sweden and the United Kingdom (Cohesion Policy - The implementation of the Integrated Territorial Investments (ITIs) by Member States, 2015). Some countries (Belgium, the Netherlands, the United Kingdom) have made progress in their regional policies in the past and are better prepared for the challenges of ITI than others. At the very beginning of the process, the implementation of the new approach brings to the forefront of all involved Member States two main issues. On the one hand, it is difficult to attract local partners and build effective communication, and on the other hand, administrative problems arise - most often due to lack of administrative capacity. It goes so far that in some Member States ITI are avoided or underestimated. This slows down the implementation of the approach by the middle of the programming period (Integrated Territorial Investments as an effective tool of the Cohesion Policy, 2019), but after the middle of the period there is an increased implementation of ITI and the achievement of integrated territorial development. Because of the integrated territorial projects, the guidelines for improvement of the regulations in the next period are outlined.

In the new programming period 2021-2027, the draft Regulation with Common Provisions (CPR) envisages a specialized territorial policy objective for "Europe closer to the citizen by promoting sustainable and integrated development of urban, rural and coastal areas and local initiatives". It expands the implementation of the approach in the EU (Updated general guidelines for preparation of projects to support the integrated territorial development of the Level 2 planning regions with funds from the European funds for the period 2021-2027, 2020). 
In Bulgaria, the strategic framework that should ensure the transition to ITI covers the period 2021-2027, and at this time (end of 2021) the strategic documents are in the process of development. In order to move to an integrated approach, changes have been made in the relevant regulatory framework. The Regional Development Act (Regional Development Act, 2020) optimizes the system of strategic documents for the implementation of the regional and spatial development policy. The levels of strategic planning of the regional policy in the new programming period are national (National Concept for Regional and Spatial Development), regional (Integrated Territorial Strategies for Development of the 6 NUTS 2 Regions) and municipal (Plans for Integrated Municipal Development). It is envisaged that the documents at regional and municipal level will have the role of territorial strategies for the implementation of integrated territorial development. The regional level in the implementation of policies is enhanced through the restructured regional development councils, which acquire territorial authority and responsibility for the actual implementation of ITI, determining the operations to be financed from various financial sources, including the ESIF. The envisaged amendments to the Regional Development Programme (Draft Regional Development Programme for the period 2021-2027, 2021) and to the Management of Resources from the European Structural and Investment Funds Act (MRESIFA) (Management of Resources from the European Structural and Investment Funds Act, 2020) containing the detailed rules for preparation and implementation of ITI have not yet entered into force. They are related to the establishment of a coordinating body and a mechanism for implementation of the integrated territorial investments, as well as a by-law to MRESIFA.

In 2019 by Decision of the Council of Ministers (DCM) №335 / 7 July 2019 (DCM № 335 of 7 June 2019 for approval of indicative financial allocation of funds from the European Social Fund+, the European Regional Development Fund and the Cohesion Fund for the programming period 2021-2027 for policy and program objectives, 2019) provides for almost all operational programmes, as well as the Rural Development Programme and the Maritime, Fisheries and Aquaculture Programme, to set aside a resource of at least $10 \%$ of the financial resources allocation for the implementation of integrated approaches to territorial development. Exceptions are operational programme (OP) "Transport Connectivity" and OP "Food and Basic Material Support". Reasonably, the program, which is mainly responsible for the implementation of ITI is OP "Regional Development", but measures and demarcation are provided in OP "Innovation and Competitiveness in Enterprises", OP "Education", OP "Environment", OP "Development of human resources", the Rural Development Program and the Strategic Plan for the Common Agricultural Policy, the Fair Transition Fund, the Instrument for Reconstruction and Sustainability.

Depending on their focus, the concepts of ITI (Updated general guidelines for preparation of projects to support the integrated territorial development of the Level 2 planning regions with funds from the European funds for the period 2021-2027, 2020) can be conditionally differentiated into territorial, sectoral and mixed ITI.

The territorial orientation is linked either to the geographical location (mountainous territory, Black Sea coast, river valley, etc.) or to a specific functional area or informal area with specific characteristics, which is predetermined within the integrated territorial strategies or determined by the participants in the partnerships. In this case, investments are focused on the specific potentials or needs of the target area through the integration of different sectoral and horizontal policies in order to socially integrate and support the local economy.

In the sectoral concepts of ITI, the emphasis is placed on the needs or potentials of a given sector in the territory, and for this purpose are envisaged combinations of infrastructural and soft measures. The sectoral concepts are focused on the respective territorial strategy and are implemented in a specific planning region of level 2. In contrast to sectoral ones, mixed concepts may include ITI from several functional or informal areas.

Whatever the concept of ITI is applied, the guiding principle remains cooperation in solving common problems on the territory, rather than focusing on its administrative-territorial boundaries.

The main goal of the policy for regional development of Bulgaria is to create vital, economically strong and sustainable regions. However, its achievement is accompanied by many challenges: deepening demographic problems, inter- and intra-regional imbalances, the pandemic situation complicated by COVID19 , and others. The approach applied in previous programming periods in determining EU funding based on sectoral priorities and the separation of rural from urban areas has led to imbalances at all levels, deepening inequalities and intensified competition between regions, municipalities and regions and within regions, between the city and its agglomeration, incl. at the settlement level, as well as within the municipalities at the micro-regional level. 
Investments in regional development acquire a more individualized approach of connection with the local context, potential and problems of the territories and promotion of the connections between the settlements and the cities. It is envisaged that the territorial approach and territorial coordination will be the basis of territorial cohesion by formulating national priorities for the different regions and types of areas to which the sectors can adapt. As part of the country's policy to increase the capacity of the regions in terms of innovation and promotion of research and development, Centres of Excellence and Centres of Competence have been established. The strategic and financial framework of the interventions in these centres, as well as their contribution to the implementation of the objectives of the Operational Program "Science and Education for Smart Growth" are of interest to a number of researchers (Bogdanova \& Terziev, 2019) (Bogdanova \& Terziev , 2019).

In line with the slow implementation of ITI in the EU, in Bulgaria, as expected, not all the necessary strategic and regulatory documents for launching ITI in the new programming period have been developed yet. The reasons for this are related to the complex nature of planning, the implementation of the bottom-up and topdown approaches and the insufficient capacity, which further slows down the process. However, despite these limitations, the individual territorial approach to planning has a huge potential to lead to the desired synergy and integration in the regional development of Bulgaria.

\section{RESEARCH OF THE CAPACITY FOR PLANNING AND IMPLEMENTATION OF REGIONAL DEVELOPMENT POLICIES IN BULGARIA}

The functions of the regional councils for the implementation of the actions planned in the strategic and regulatory framework in connection with the implementation of ITI can be assessed as determining the outcome of the implementation of the new approach in planning. For this reason, having or building adequate capacity to implement regional public policies through ITI is essential.

The rights and obligations imposed on the Regional Councils in connection with the integrated territorial strategies for regional development for planning by NUTS 2 under the Regional Development Act and the regulations for its implementation require a high degree of knowledge of planning processes and their impact on regional development. The main responsibilities of the Council are related to the coordination and implementation of the state policy for regional development in the respective region level 2, which in practice is a complex task caused mainly by two factors: the complexity of the planning processes and their coordination and the heterogeneity of the territory included in the scope of the individual planning regions.

The composition of the regional development councils includes the regional governors, mayors and chairmen of municipal councils, located on the territory of the region, elected in accordance with the respective order. The list of representatives of organizations with an advisory vote is wide. As such, central departments, scientific and branch employers 'and workers' organizations, associations and civil society structures are included. They are supported by an expert panel, which is organizationally structured in three units: a mediation unit, a public consultation unit and a pre-selection unit. If the first two units have rather functions to ensure the participation of stakeholders in the processes of formulation and implementation of public policies, incl. and with regard to the creation of joint partnership integrated projects and the provision of public support for them, the pre-selection unit has mainly expert-operational. This distinction is the basis for outlining different requirements regarding the skills and competencies for planning of the included experts in the composition of the units.

As the regional councils mainly consist of representative political and leading figures, the operational planning work of the councils will be concentrated in expert units. This raises the question of the necessary knowledge and skills to ensure the planning process, both at operational and strategic level, and to ensure the analytical and information security of management decisions within regional development councils.

In the period from 30 August 2021 to 10 September 2021, a survey was conducted on the organizational mechanism for the implementation of integrated territorial investments at the regional level. The aim was to establish the degree of preparation of the involved public authorities and their experts with the implementation of regional development policy at NUTS2 level according to the defined powers of the regional councils and their expert units. The survey was conducted electronically, and by e-mail it was sent to 265 municipal administrations, 28 district administrations, 27 regional information centers, 1 ministry Ministry of Regional Development, 6 regional development councils, 28 regional development councils, National Association of Municipalities, Confederation of Employers and Industrialists in Bulgaria (CEIBG) - as part of the observers with the right to an advisory vote in the Regional Development Councils (PCDs), Confederation of Labor (CLs) "Support", Confederation of Independent Trade Unions in Bulgaria (CITUB). The scientific community, non-governmental organizations and other members with an advisory vote in the 
regional development councils were not the subject of the survey. The collection of answers was carried out by the method of the respondents, as 149 completed questionnaires were registered within the indicated term. The results presented in the summary below are derived on the basis of a descriptive analysis of data distributed on a certain basis. The survey is not representative and the sample was formed according to the method of the respondents.

A significant number of respondents believe that the planned expert structure of the regional development councils, including mediation, public consultation and pre-selection units, is sufficient to ensure the implementation of the integrated territorial investment approach. Almost $20.4 \%$ give a definite positive answer, while $44.9 \%$ are not so definite. Not a small part - $16.3 \%$ are skeptical about the expert structure and just, as much cannot give an assessment.

Regional policy, regional development, strategic planning and public policies and programs are the areas in which experts involved in mediation and public consultation units must have knowledge and a high level of awareness. Knowledge in the field of various project management processes respondents indicate as insignificant for these units. With regard to the necessary competencies, soft skills related to negotiation and flexible communication, teamwork, coordination, organization, facilitation are indicated as extremely important. According to the respondents, foreign language skills, technological design and programming, autonomy and leadership skills, work ethic and emotional intelligence are not so important. The knowledge and skills that the experts involved in the mediation units should have are placed on one plane, i.e. 93.9\% of respondents rate them as equally important, $2 \%$ believe that skills are leading, and for the remaining $4.1 \%$ both are irrelevant.

Regarding the presence or absence of knowledge and skills in the units of the regional development councils regulated in the Regional development act (RDA) and Regulations for implementation of the Regional development act, (RIRDA) units, a little more than half of the respondents - $51 \%$ indicate that, that the experts from the regional information centers, who will also be experts in the units for mediation and public consultations, have the necessary knowledge and competencies to fulfill these commitments, almost $10.2 \%$ of the respondents give the exact opposite answer, and the remaining $38.8 \%$ do not engage with such.

The knowledge of the experts involved in the pre-selection units, which are assessed as necessary, are in the following areas: European development policy, regional development, regional planning, public policies and programs, overall project administration. Knowledge of project management in the part of human resources, supplies, quality, as well as in terms of financial management and control and methodologies for statistical measurement and evaluation are indicated as insignificant. In terms of competencies, those related to teamwork, functional literacy, logical thinking, critical thinking and analysis, organization are mentioned as important. Insignificant for these experts, according to the respondents, are autonomy and leadership in work, active learning, social influence, foreign language training and the skills for argumentation, problem solving, generating ideas, etc. The knowledge and skills of the selection units were also assessed as equally important by $93.9 \%$ of the respondents. Accordingly, $2 \%$ rated skills as the most important and just as much knowledge. Again, $2 \%$ believe that skills and knowledge are irrelevant.

Regarding the level of preparation of the experts in the transmission selection units, who are representatives of the territorial unit of the Ministry of Regional Development and Public Works, the answers vary significantly. Only $10.2 \%$ give a categorically positive answer about the existing expertise. $26.5 \%$ of the respondents have some hesitations regarding the level of readiness of the experts, and a significant part of the respondents believes that it is rather not at the required level $-32.7 \%$. Just over $10 \%$ are adamant that the necessary expertise is not available in the pre-selection units.

Over $69 \%$ of the respondents have positive expectations from the implementation of the integrated territorial investments at regional level in the period 2021-2027. At the other pole are $16.3 \%$ and the remaining $14.3 \%$ have no expectations. The available capacity of the regional and municipal administrations has the greatest influence on the formed assessment, followed by the capacity of the regional information centers and the experts in the regional development councils, as well as the capacity of the beneficiaries and the established mechanisms for work organization, coordination and coordination between the managing authorities. Interestingly, the regulatory and strategic framework in the field of regional development, as well as the organizational provisions and imposed rights and obligations of the Regional Development Councils in connection with the implementation of the integrated approach to regional development are not influential in shaping the expectations of respondents.

A more in-depth correlation analysis shows that those holding positions at management level at directorate, department or unit are much more cautious in their responses to the expected impact of implementing 
integrated territorial investments to achieve balanced regional development. They point to both hard and soft competencies as important for regional council units, while respondents who hold an expert position with analytical functions focus on knowledge in the field of regional policy and regional development, and less on skills such as autonomy and leadership at work, active learning, creativity, innovation, creativity, etc. Their expectations regarding the new for Bulgaria integrated approach for regional development are even higher, as they are based on a higher assessment of the existing expert potential. It should be noted that the respondents from the South-Western planning region have more positive attitudes for the programming period 2021-2027 towards each of the regions in Northern Bulgaria. The difference in economic development between northern and southern Bulgaria is the main reason for the different expectations of the respondents.

\section{THE COMPETENCE APPROACH IN SUPPORT OF PLANNING}

The economic reality characterized by constant changes, crises, dynamics, instability, unpredictability, puts the focus of managers on finding adequate solutions. The challenges faced by the specialist performing planning activities, compiling planning documents, incl. programs, projects, plans, strategies, etc. require the search for alternatives to deal with them.

Quite adequately, in response to these and other similar problems, organizations are looking for ways to find, improve, upgrade and use these traits, behaviours, activities in specialists performing planned functions, to identify and select the unique, appropriate, brilliant implementation of goals and tasks from the mediocre. Different sectors, countries and regions use different approaches to find a common ground between common, national and sector-specific points of reference related to the need to reorganize human resources systems to make the most of the opportunities that can and should suggest the specialists dealing with planning.

Digitalisation and globalization, including human resource management in the field of regional development, lead to obstacles and a rapidly changing environment. The framing of the necessary, experience, knowledge, skills, etc. necessary for the definition of the key competencies for the planning specialist is important in order to build adequate capacity in the regional councils and in other units, charged with ITI implementation functions. Researchers (Leinonen, 2021) point out the importance of the connection between the integration of the developed strategies with the organizational and personal development. Providing this connection, gaining knowledge and building skills is a complex task that can be solved with the help of the competence approach. Unlike most outdated human resource management systems, which lack synchrony, integration and coherence between their different parts, functions and levels (STRATEGMA Agency, 2011), this approach ensures the integrity between the organizational-administrative paradigms and the practice regarding the development of human resources.

The reasons for using the competence approach in support of planning are diverse. At a time when the dynamics of the environment, complex competitive relations and imposed administrative practices make the work of the planner complex, the achievement of planning tasks difficult, the role of expertise of the human factor as a key to success stands out. The results, in the short run, and the long-term impacts of the application of the ITI approach will depend on the ability of the organizations to identify, find, create and manage the competencies of the human capital (planning specialist). To achieve the desired goals in regional development, in the most effective way possible, administrations need to be able to mobilize, motivate, stimulate and develop specialists (Lewi-Dumont, 2011) in planning.

The implementation of ITI in the public policies for spatial and regional development requires the search and building of appropriate knowledge, values, skills and experience of the planning specialists, which will ensure high quality of the operational implementation of the work in the units of the regional councils. This is necessary given the importance of regional development, on the one hand, and the complexity of integrated policies, on the other. In combination with the need for broad participation of stakeholders, communication with a large number of representatives of public institutions with different territorial interests, the requirements for the expertise of employees in the units becomes even higher. The application of a standard organizational approach to the competencies for the respective planning positions is an appropriate tool also with regard to the public institutions, incl. and for those entrusted with the functions of implementing public policies and regional development through ITI.

The algorithm of application of the competence approach includes setting goals, analysis of resources (including human, technological and financial), development of a plan for implementation of the approach, development of a competence model (including definition of criteria for good presentation, inspection and analysis), synchronization with the implemented and operating systems in the organization, evaluation of the results, review and identification of actions in case of non-compliance. It is important to consider the 
environmental factors at the entrance of the process - normative, strategic and methodological framework, existing practices, lessons learned, current models, etc.

The development, implementation and application of the competency approach is a tool for better labor performance, which is crucial for the planning processes that will take place within the regional councils in connection with the implementation of public policies based on ITI. Efforts should be aimed at attracting specialists who have knowledge in the field of planning science and who have or are in the process of building the necessary competencies. The development of a competency model, including a system for assessing the level of competencies, analysis of training needs, training of specialists, engagement in the development, planning and construction of the competency model in a real environment (Nikolova, 2014) are issues that should be decided in order to improve the overall capacity of employees engaged in planned activities, incl. and in regional development councils. Modern economic dynamics requires flexibility of decisions and actions in the implementation of planning activities, in this sense it could be said that the competence approach is a flexible and synchronized management tool through which to outline the profile of the planner.

\section{CONCEPT FOR COMPETENCE MODEL OF THE PLANNING SPECIALIST}

The concept of competencies began in 1973 with David McClelland's article "Better Testing Competences Than Intelligence" (McClelland, 1973). As a result, in recent decades the focus of attention of scientists, practitioners, managers and employees in human resources management units has shifted from the traditional assessment of knowledge and skills to their practical application in real conditions. Increasing emphasis is placed on competencies related to the ability of individuals to successfully cope with various challenges in a dynamic environment, combining knowledge, skills and experience. Based on the preferred, sought-after and desired competencies, competency models emerge, which are a set of complementary competencies that indicate what behaviour officials in the organization should demonstrate in order to achieve organizational goals. There are two important features with regard to competency models: first, they are not job descriptions, as they do not describe what individuals should do, but focus on how they should do their job; and second, while job descriptions are prepared by human resource management units, competency models are compiled by the managers. The main emphasis in the methodological developments in the field of competencies (Hubanova, Koynova, \& Georgiev, 2011) (Padalski, Hubanova, \& Georgieva, 2010 ) is the understanding that competency models should meet the goals of the organizations for which they are created.

In organizational and methodological terms, the issue of competencies and competency models is covered by the European Qualifications Framework (European qualifications framework, 2017) and the National Qualifications Framework of the Republic of Bulgaria (National Qualifications Framework of the Republic of Bulgaria, 2012). A National Reference Network has been established, which organizes and coordinates the processes for compiling competency models and their subsequent implementation in the organizations of practice, as well as an Information System for Competency Assessment (National Competency Assessment System, 2021), containing competency standards of over 500 positions in 25 economic sectors. As of September 2021, the created database lacks a competency model in the field of planning. This absence is probably due to an underestimation of the importance of the planning function, but economic logic requires a similar model to be developed for planners.

Theory and practice offer a variety of different types of competency models (Padalski, Hubanova, \& Georgieva, 2010), but since the focus of the research is the planning specialist, the most suitable for this purpose is the Competence Model by position. When compiling this type of competency model, the competency profile occupies a key place, which is a synthesis of those competencies that are most directly related to the requirements for the specific position. These competencies determine what behaviour managers expect from those who hold certain positions so that they can contribute to achieving the goals of the organization.

Considering the nature of the work, the specifics and responsibilities of the planning specialist, we believe that his competency profile should focus on the following competencies (in alphabetical order):

- Analytical thinking (transferable competence) - To what extent he applies critical study of information, analysis, synthesis, interpretation and evaluation of data, tracing of logical and causal relationships, use of induction and deduction, formulation of conclusions and recommendations.

- Application of experience and knowledge to new situations (transferable competence) - To what extent he manages to apply in his work accumulated experience from previous periods / situations, analyses, synthesizes and formulates conclusions and ideas in performing current tasks, which he can apply in future 
periods, successfully finds the necessary relevant information that would be useful in a particular situation.

- Application of normative regulations and standards (specific competence) - To what extent he knows and applies in his work the current normative base and standards, related to the activity of the organization, the internal company rules and procedures, monitors for possible changes and takes corrective actions, if necessary.

- Cross-functional cooperation (transferable competence) - To what extent he cooperates with colleagues from other units / departments, shares and exchanges experience and knowledge, works in an atmosphere of collegiality, teamwork, participates in joint initiatives and tasks.

- Development of market strategies and policies (specific competence) - How well he analyses the current state of the organization, knows the environment, the main factors and conditions, develops strategic documents in order to achieve company goals, justifies and motivates priorities and activities, analyses the current implementation of existing strategies and policies and, if necessary, offers corrective measures.

- Document handling (specific competence) - To what extent he knows and applies the rules for the document turnover in the organization, prepares documents in compliance with the applicable requirements, stores and archives documentation.

- Forecasting (specific competence) - How well he knows the state and development of economic processes and phenomena, the business environment, has reliable and reliable sources of information, applies various models for research, data analysis, trend detection and forecasting for future activities of the organization.

- Operational planning (specific competence) - To what extent he takes into account all factors and conditions relevant to the preparation of plans, monitors their ongoing implementation, and if necessary makes motivated and justified proposals for their adjustment.

- Planning (transferable competence) - To what extent he knows and applies appropriate to the task, factors, situation or other conditions planning tools, successfully prioritizes its tasks and organizes his work in order to achieve the set priorities and goals, while respecting time and other constraints, competently uses the provided resources.

- Professional expertise (specific competence) - To what extent he effectively applies the knowledge, skills and experience in his work, prepares competent analysis, reports, develops plans, makes purposeful efforts to upgrade and update his professional competencies.

- Strategic planning (specific competence) - The extent to which he applies appropriate methods for strategic analysis of the internal and external environment, competitors, correctly identifies the strengths and weaknesses, opportunities and threats, proposes measures to increase competitive advantages, uses opportunities and neutralizes threats, develops well-founded and clearly correspond to the organization mission, vision, goals, strategy, priorities, measures and activities.

- Work with digital technologies (portable competence) - How well he works with modern office equipment, hardware and software, incl. specialized one, creates, finds, stores and manages databases, creates and edits content.

The proposed competence profile of the planning specialist contains 12 applicable competencies, which directly correspond to the specifics of the work of the planner and his expected behaviour, in order to achieve organizational goals. They can be developed in specific skills to ensure the adequacy of the functions performed by the experts engaged in the implementation of public policies based on ITI.

\section{INFORMATION AND COMMUNICATION TECHNOLOGICAL (ICT) COMPETENCIES OF THE PLANNER}

By definition, the very idea of digitalization and digital transformation is the assimilation of new projects and new activities through the implementation and practical application of digital and ICT technologies. In this sense, the leading goal can be defined as the assimilation of new processes, increasing the efficiency of management. The digitalization of planning and management processes reveals many opportunities and ultimately leads to the acquisition of lasting benefits. In many cases, there is even a rethinking of what are considered key, fundamental issues and problems. The most significant commitment in digitalization is the implementation of digital and ICT technologies in existing processes in order to optimize activities and increase their efficiency through ascending gradation based on the use of digital data. 
In addition to determining the set of information that the individual functional units and entities exchange with each other and concentrate for the needs of management, it is especially important to choose the elements of the main digital tool (Yankov, 2021). Through them: transparent communication will be achieved; the whole set of information and data will be accumulated and concentrated; quick and easy analysis of data and results will be facilitated; the processes in the strategically important directions and activities will be digitalized and automated to a large extent.

One of the most important risks that can threaten the successful implementation and application of such a digital system is the risk associated with lack of competencies. This risk manifests itself mainly in two directions. First, as a lack of competencies and experience of the team involved in the implementation of the system. This uncertainty can be expressed in various aspects related to inaccurate and untimely actions for the adaptation of the respective software modules, their testing, as well as their overall setup. Second, as a lack of competencies and human resources in the organization - user of the system. It is indisputable that even the most modern digital solutions do not develop their potential and software functionalities without the presence of adequate human intervention. In both cases, the provision of technical competencies is only one part of what is needed - organizational competencies are needed to reengineer the relevant processes in a way that does not jeopardize the integration and normal operation of the user organization (Aleksandrova, 2021).

Human resources should be prepared for such an organizational change, through the gradual establishment of new working relationships, introduction of new "good" practices for regular data exchange between different units, building competencies for working with the new digital tool (technological and for team work). A good example of this is 'training of trainers', which gradually builds the necessary new competencies and upgrades the organizational culture that promotes loyalty to new values.

When we talk about digital and ICT competencies, we mean not only the possession of digital competencies for working with the system, but also the acquired competencies and understanding of "business management". Key users must have a wide range of competencies, including outside the field of purely technical knowledge. For example, teamwork skills, good knowledge of business processes in the company, interests in the field of good practices (Stefanova, 2012). A new type of additional competencies is becoming more and more decisive - competencies for analysis and decision-making. These are knowledge, skills, ability, experience, specialty (special opportunity) for the transformation of "raw" databases into "meaningful" planning and management information to support the development and functioning of organizations. That is why it is so important for planners to have the competencies to work with data processing and management software, and to generate clear visualization tables (dashboards). This is valid as well for data presentation models that benefit other units and entities in the organization.

Competences for analysis and decision-making are a set of knowledge, skills, experience and management of various processes, tools and technologies that are needed to transform data into management information, and information into management decisions and plans, involving rapid and effective actions. These competencies boil down to: (Business Intelligence solutions - what, for whom and why, 2019)

1. Active support in the formulation of effective and informed decisions;

2. Transforming the large volume of information into valuable content;

3. Facilitating the accessibility, exchange, processing and analysis of information by "the right people, at the right time and in the way, they prefer";

4. Preservation of knowledge in the organization;

5. Minimize the time and resources.

In an even more detailed context, these competencies are expressed in: (Pizhev, 2017)

- Technical knowledge of SQL and other tools and platforms (e.g. Tableau, OBIEE and BOBJ);

- Extraction, processing and analysis of data from many different sources and management systems;

- Skills for conducting comparative, prescribing and predictive analysis;

- Ability to synthesize data and present it through visualization tables, metrics and reports;

- Creation and maintenance of databases;

- Ability to create models and variations; 
- Ability to apply Agile and/or Lean methodologies; possessing excellent communication skills.

Possession of the competences for analysis and decision-making by the planners is in fact a key tool for extracting the most useful value from this information, through its processing, extraction and systematization according to determining efficiency indicators. Possessing competencies for analysis and decision-making allows planning and management specialists to synthesize certain models, patterns and causal relationships. This makes it easier to produce reports, inquiries or visualization techniques to help managers at different management levels to see the changes in the processes in a dynamic context. And to develop and take quick, accurate and adequate decisions on the way to achieving the goals, for the realization of benefits and / or for the regulation of low-efficiency activities and units

\section{DISCUSSION}

The challenges for the planned activity are related to the improvement of technologies as well as to the increasingly dynamic and difficult to predict environment. Therefore, soft skills are extremely important for making adequate management and planning decisions. Numerous and different interests in public policies require a high degree of awareness, coordination and integration, consensus, autonomy, leadership skills. All this is part of the soft competencies, the development of which is a long learning process (Bogdanova, 2018). There is a lack of broad public understanding of the importance, role and function of the planner in an organization, institution or system. The training in planned disciplines is poorly represented, which leads to a lack of hard skills in this field. The challenge is to build a detailed model of the knowledge, skills and competencies that an expert planner who performs functions in support of regional and spatial development must possess. This issue is debatable and is part of the agenda of the public authorities in Bulgaria, which are responsible for managing regional development in the programming period 2021-2027.

\section{REFERENCE LIST}

Aleksandrova, M. (9 2021 r.). Risks in the implementation of ERP-systems in Bulgarian business organizations. Извлечено от https://balbg.com:

https://balbg.com/publications/Matilda\%20Aleksandrova/Riskove\%20pri\%20vnedriavane\%20na\%20 ERP.doc

Bogdanova, M. (2018). Policies and Instruments for Social Development. Journal of Innovations and Sustainability, pp. 59-63.

Bogdanova, M., \& Terziev , V. (2019). Strategic and financial frame of intervention-centers of excellence and centers of competence . International E-Journal of Advances in Social Sciences,, pp. 156-167.

Bogdanova, M., \& Terziev, V. (2019). Bogdanova, Margarita et al. Defining the Goals in OP "Science and Education for Smart Growth" in Compliance with the Needs / /. International E-Journal of Advances in Social Sciences, pp. 175-184.

Business Intelligence solutions - what, for whom and why. (01 2019 r.). Извлечено от https://www.balkanservices.com/blog/business-intelligence-reshenia-kak-kakvo-za-kogo-i-zashto/

Cohesion Policy - The implementation of the Integrated Territorial Investments (ITIs) by Member States. (October 2015 r.). Извлечено от CCRE CEMR Local and Regional Europe: https://www.ccre.org/img/uploads/piecesjointe/filename/CEMR_Study_ITI_EN-0.pdf

Cohesion Policy - The implementation of the Integrated Territorial Investments (ITIs) by Member States. (2015). Извлечено от CCRE CEMR Local and Regional Europe: https://www.ccre.org/img/uploads/piecesjointe/filename/CEMR_Study_ITI_EN-0.pdf

DCM № 335 of 7 June 2019 for approval of indicative financial allocation of funds from the European Social Fund+, the European Regional Development Fund and the Cohesion Fund for the programming period 2021-2027 for policy and program objectives. (2019). Извлечено от SINGLE INFORMATION PORTAL OF THE EUROPEAN STRUCTURAL AND INVESTMENT FUNDS: https://www.eufunds.bg/sites/default/files/uploads/eip/docs/2019-07/19RH335.pdf

Draft Regional Development Programme for the period 2021-2027. (Мау 2021 r.). Извлечено от Operational Program "Regional Development": http://www.bgregio.eu/media/Programirane/2021-2027/05.05.21- 
PDR_new\%20template_BG\%20april.pdf

European qualifications framework. (2017). Извлечено от https://europa.eu/europass/bg/europeanqualifications-framework-eqf

Hubanova, G., Koynova, N., \& Georgiev, V. (2011). Methodical instructions for design, approbation, testing and verification of sectoral and company competence models and maps for assessment of the competences of the workforce. Sofia.

Integrated teritorial investments. (May 2014 r.). Извлечено от https://ec.europa.eu/regional_policy/sources/docgener/informat/2014/iti_bg.pdf

Integrated Territorial Investments as an effective tool of the Cohesion Policy. (March 2019 г.). Извлечено от EP: https://www.europarl.europa.eu/cmsdata/162823/25032019_CONT_Briefing_ITI_Final.pdf

Leinonen, S. (September 2021 r.). Taking a competence-based approach. Извлечено от https://www.tuni.fi/tlc/en/planning-and-implementation-of-teaching/curriculum-work/competencebased-approach/

Lewi-Dumont, N. (2011). Competence approach in France. INS-HEA Suresnes ,France.

Management of Resources from the European Structural and Investment Funds Act. (June 2020 r.). Извлечено от https://www.lex.bg/bg/laws/ldoc/2136715858

McClelland, D. (1973). Testing for Competence Rather than for "Intelligence”. American Psychologist, 28,1 14. Извлечено от https://www.therapiebreve.be/documents/mcclelland-1973.pdf

National Competency Assessment System. (2021). Извлечено от https://mycompetence.bg/bg/

National Qualifications Framework of the Republic of Bulgaria. (2012). Извлечено от https://www.aubg.edu/documents/1536

Nikolova, I. (2014). Application of the competence approach. Alternative.

Padalski, D., Hubanova, E., \& Georgieva, E. (2010). Methodology for developing a competency model. Methodology for defining the competencies and creating a competency model at the level of company, sector and region. National Competency Assessment Network.

Pizhev, D. (04 2017 r.). Profession: BI specialist. Извлечено от https://www.karieri.bg/news/36558_profesiia_bi_specialist

Regional Development Act. (March 2020 r.). Извлечено от Ministry of Regional Development and Public Works: https://www.mrrb.bg/bg/zakon-za-regionalnoto-razvitie/

Regulation (EU) № 1303/2013 of the European Parliament and the Council. (2013). Извлечено от https://eur-lex.europa.eu/legal-content/BG/TXT/PDF/?uri=CELEX:32013R1303\&from=bg

Stefanova, D. (2012). Training makes sense of investing in ERP. Извлечено от https://enterprise.bg/blognews/o\%D0\%B1\%D1\%83\%D1\%87\%D0\%B5\%D0\%BD\%D0\%B8\%D0\%B5\%D1\%82\%D0\%BE$\%$ D0\%BE\%D1\%81\%D0\%BC\%D0\%B8\%D1\%81\%D0\%BB\%D1\%8F\%D0\%B8\%D0\%BD\%D0\%B2\%D0\%B5\%D1\%81\%D1\%82\%D0\%B8\%D1\%86\%D0\%B8\%D1\%8F\%D $1 \% 82 \% \mathrm{D} 0 \% \mathrm{~B} 0-\% \mathrm{D} 0 \% \mathrm{~B} 2-\mathrm{erp}$

STRATEGMA Agency. (2011). Development of variants of a model for improvement of the system for evaluation of the performance of the employees in the state administration. Sofia.

Updated general guidelines for preparation of projects to support the integrated territorial development of the Level 2 planning regions with funds from the European funds for the period 2021-2027. (November 2020 r.). Извлечено от Operational Program Growing Regions: https://www.eufunds.bg/sites/default/files/uploads/oprd/docs/2021-09/03.11.20Guidance\%20for_integrated_projects_territorial\%20priority.pdf

Yankov, В. (9 2021 r.). Digitalization of marketing and trade processes: how to implement it. Извлечено от https://limacon.bg/sales/blog/digitalizatsiya-na-marketing-tyrgovski-protsesi 